\title{
Cardiorenal Syndromes
}

Ronco C, Bellomo R, McCullough PA (eds): Cardiorenal Syndromes in Critical Care.

Contrib Nephrol. Basel, Karger, 2010, vol 165, pp 112-128

\section{Acute Heart Failure Treatment: Traditional and New Drugs}

\author{
Mihai Gheorghiade ${ }^{a}$ Alberto Palazzuolib • \\ Claudio Roncoc \\ aDivision of Cardiology, Northwestern University Feinberg School of Medicine, Chicago, III., USA; \\ ${ }^{b}$ Department of Internal Medicine and Metabolic Diseases, Cardiology Section University of Siena, \\ Siena, and 'Department of Nephrology, Dialysis \& Transplantation, International Renal Research \\ Institute, San Bortolo Hospital, Vicenza, Italy
}

\section{Retraction}

"Acute Heart Failure Treatment: Traditional and New Drugs"

by Gheorghiade M, Palazzuoli A, Ronco C. Contrib Nephrol, 2010;165;112-128.

This chapter has been retracted at the authors' request. A miscommunication between the corresponding author and the co-authors resulted in the publishing of an unfinished article. 